\title{
A STUDY OF SERUM HOMOCYSTEINE LEVEL IN PATIENTS WITH SUBCLINICAL HYPOTHYROIDISM
}

\author{
Nithi Mahanta1, Deepika Lahon², Barnali Bhattacharya Thakur ${ }^{3}$
}

1Postgraduate Trainee, Department of Biochemistry, Gauhati Medical College and Hospital.

${ }^{2}$ Associate Professor, Department of Biochemistry, Gauhati Medical College and Hospital.

${ }^{3}$ Associate Professor, Department of Biochemistry, Gauhati Medical College and Hospital.

\begin{abstract}
\section{BACKGROUND}

Subclinical hypothyroidism is defined as a persistent elevated serum Thyroid stimulating hormone (TSH) level with a normal serum thyroxine (FT4) concentration. This condition has evolved as a risk factor for many metabolic conditions and cardiovascular abnormalities. This study attempts to determine the relationship between subclinical hypothyroidism and homocysteine, which is recognised as an independent risk factor for accelerated atherosclerosis.

Aims and Objectives- To evaluate the serum homocysteine level in patients with subclinical hypothyroidism and euthyroid healthy controls and to find out the correlation between serum homocysteine level and thyroid profile (if any).
\end{abstract}

\section{MATERIALS AND METHODS}

The study was conducted in a group of individuals consisting of 45 normal healthy subjects and 45 newly diagnosed cases of subclinical hypothyroidism attending Department of Endocrinology and Department of Medicine of Gauhati Medical College. Assessment of serum homocysteine was done by ELISA technique in Lisa Scan EM microplate ELISA reader, serum TSH and FT4 was estimated by VITROS 5600 Autoanalyzer. Statistical significance and correlation were assayed using independent " $t$ " test and Pearson's correlation test.

Study Design- Descriptive comparative.

\section{RESULTS}

Analysis of data reveals that the mean Homocysteine level in case group was significantly higher than in control groups. A positive correlation was observed between TSH and Homocysteine levels in the case group and a negative correlation was observed between FT4 and Homocysteine level in the case group.

\section{CONCLUSION}

The present study shows that the patients with subclinical hypothyroidism have higher levels of Serum Homocysteine, which may be the cause of various cardiovascular complications involved with subclinical hypothyroidism.

\section{KEYWORDS}

Homocysteine, Subclinical Hypothyroidism, Thyroid Stimulating Hormone, Thyroxine.

HOW TO CITE THIS ARTICLE: Mahanta N, Lahon D, Thakur BB. A study of serum homocysteine level in patients with subclinical hypothyroidism. J. Evolution Med. Dent. Sci. 2018;7(04):454-458, DOI: 10.14260/jemds/2018/101

\section{BACKGROUND}

Subclinical hypothyroidism is also known as mild thyroid failure. The condition is defined as an elevated serum thyroid stimulating hormone (TSH) level with a normal serum thyroxine (FT4) concentration. ${ }^{1}$ Subclinical hypothyroidism is accidentally diagnosed and usually presents with mild or no symptoms of hypothyroidism, but it may progress to overt hypothyroidism. ${ }^{2}$ It may be associated with manifestations that can be managed by treatment. ${ }^{1-4}$

Today subclinical hypothyroidism is a common biochemical finding in the general population. Overall, the population prevalence of subclinical hypothyroidism is around $3 \%-8 \%$. It is found to be more common in women and increases with increasing age and is higher in white than in black population. . $^{-10}$

'Financial or Other Competing Interest': Dr. Mahanta reports grants from $D B T$, during the conduct of the study.

Submission 01-12-2017, Peer Review 07-01-2018,

Acceptance 13-01-2018, Published 22-01-2018.

Corresponding Author:

Dr. Nithi Mahanta,

Postgraduate Trainee, Department of Biochemistry,

Gauhati Medical College and Hospital.

E-mail: drnithimahanta@gmail.com

DOI: $10.14260 / \mathrm{jemds} / 2018 / 101$
A TSH level greater than $10 \mu \mathrm{IU} / \mathrm{mL}$ predicts a higher rate of progression to overt state than a level of less than 6 $\mu \mathrm{IU} / \mathrm{mL} .{ }^{9}, 10$ Although, labelled as SCH there may be symptoms like muscle cramps, constipation, puffy eyes, cold intolerance, hoarseness of voice, fatigue, depression, neuromuscular symptoms and menstrual abnormalities. ${ }^{9} \mathrm{SCH}$ may be associated with a modest increase in the risk of coronary heart disease and mortality, particularly in subjects with higher TSH levels. Thyroid hormones are known to affect the heart and vasculature and as a result the impact of SCH on the cardiovascular (CV) system has recently become an important topic of research.

Homocysteine is sulphur containing non-protein $\alpha$-amino acid. The concentration of plasma homocysteine is regulated by several factors, which include genetically determined metabolic enzyme alteration, environmental factors, vitamin B6 and folic acid deficiency. Abnormally, high serum homocysteine levels is known as hyperhomocysteinaemia, conventionally described as above $15 \mu \mathrm{mol} / \mathrm{L}$. It can however be classified as mild (15 - $30 \mu \mathrm{mol} / \mathrm{L})$, moderate $(31-100$ $\mu \mathrm{mol} / \mathrm{L}$ ) and severe ( $>100 \mu \mathrm{mol} / \mathrm{L}$ ) according to the disease severity. Serum total homocysteine level has been recently postulated as an independent risk factor for accelerated atherosclerosis. 11 
Meta-analysis of cross-sectional studies have suggested that increased serum Homocysteine concentration is associated with 60 percent increase in the incidence of cardiovascular diseases.12,13 Homocysteine is an unstable amino acid. In hyperhomocysteinaemia, homocysteine undergo autooxidation and produces reactive oxygen species. These reactive oxygen species, which are produced inactivates and deplete nitric oxide and impair endothelial thrombomodulin expression that leads to activation of contact pathway for intrinsic coagulation in endothelial cells. All these factors lead to endothelial damage and dysfunction. ${ }^{14,15,16}$

Increased incidence of cardiovascular diseases in subclinical hypothyroidism cannot be fully explained by an atherogenic lipid profile.17,18,19 Thyroid hormones are physiologic modulators of both tissue oxidative stress and protein degradation. The mechanism linking hypothyroidism and oxidative stress is unknown. Oxidative stress increases the concentration of oxidised Low-Density Lipoprotein (LDL). Homocysteine also induces LDL oxidation. Hyperhomocysteinaemia in subclinical hypothyroidism may probably be due to reduced renal excretion and reduced metabolism of homocysteine. ${ }^{20}$ Subclinical hypothyroidism may be a potentially modifiable risk factor of cardiovascular disease and mortality.

Data regarding association of homocysteine and subclinical hypothyroidism is very limited in North-East India. A strong correlation between serum total homocysteine and subclinical hypothyroidism may have important medical implication in the prevention and treatment of cardiovascular diseases. ${ }^{21}$

\section{Aims and Objectives}

- To evaluate serum homocysteine level in patients with subclinical hypothyroidism and euthyroid healthy controls.

- To find out the correlation between serum homocysteine level and thyroid profile (if any).

\section{MATERIALS AND METHODS}

Study Design- Descriptive comparative.

The present study was conducted in the Department of Biochemistry, the Department of Medicine and the Department of Endocrinology of Gauhati Medical College and Hospital, Guwahati from July 2016 to July 2017. This work has been sanctioned by the Institutional Ethics Committee, Gauhati Medical College via letter no MC/217/2016/95 Dated 01/09/2016. Moreover, informed consent for participations in the study was obtained from the subjects after explaining them the significance of the tests, the aim of the study and the anticipated results. This was a cross-sectional comparative study, wherein a thorough history and detailed physical examination and relevant laboratory investigations were done.

\section{The Study was to be conducted in Two Broad Groups- Case}

45 (forty-five) newly diagnosed, subclinical hypothyroid patients, more than 18 years of age were included in the test group. These patients were diagnosed in the Medicine or Endocrinology Department with raised TSH level with normal fT4 level.

\section{Control}

This group includes age and sex matched 45 subjects in euthyroid status. Subjects for the control groups were selected randomly among persons from different sectors of the society belonging to diverse socio-economic status who are apparently healthy. All individuals of the control group co-operated voluntarily. The individuals selected for this group were of either sex and of different age groups.

\section{Inclusion Criteria}

The case group included patients more than 18 years of age with raised serum TSH level and normal serum fT4 level. The control group included normal healthy individuals more than 18 years of age in euthyroid state.

\section{Exclusion Criteria}

Patients with Diabetes Mellitus, Pre-existing Hypertension, Pregnancy, Chronic Renal disease, Patient taking anti-folate drugs, Cardiovascular Disease and Patients taking levothyroxine were excluded. A careful screening was done in selecting subjects, so that persons having pathology referable to any system either in the past or present, any recent infection and surgery were not included in this group. A thorough history (personal, occupational, etc.) and physical examination was done to exclude all those possibilities.

\section{Methods of Evaluation}

Assessment of serum Homocysteine was done by Elisa technique in Lisa Scan EM microplate ELISA reader, serum TSH and FT4 was estimated by VITROS 5600 Autoanalyzer, Fasting plasma glucose, serum creatinine, serum AST and serum ALT were measured using Merck Microlab 300 Semiautoanalyzer. All the chemicals used in the study were of analytical grade and de-ionised water was used. For Blood Sugar, Serum Creatinine, Serum AST and ALT determination, kits obtained from Coral Clinical Systems were used. For serum Homocysteine determination, Human Homocysteine (Hcy) ELISA Kit was used which was obtained from Sincere Biotech Co. Ltd. and TSH and FT4 was measured using VITROS immunodiagnostic reagent product. Statistical significance and correlation were assayed using independent " $t$ " test and Pearson's correlation test by using Graph Pad in Stat version 3.00 for Windows, GraphPad Software, San Diego, California.

\section{RESULTS}

In the present study, the age distribution of the individuals in the study group was between 20 and 75 years. The mean age of subjects in Case and Control Group was $44.956 \pm 11.668$ years and $42.178 \pm 10.562$ years, respectively. The maximum numbers of patients were in the age group of $40-49$ years, which constituted $34 \%$ of the total subjects. We could not find any significant correlation between age and homocysteine concentration in the case group with Correlation coefficient $(r)=0.0125, P$ value is 0.934 . The majority of the patients in the study population were females, who constituted $58 \%$ of the case and the control group. Only 42\% were males. The male: female ratio was 21: 29. 
Fasting plasma glucose was measured in both case and control groups, and the mean FPG in case and control groups are $95.33 \pm 14.151 \mathrm{mg} / \mathrm{dL}$ and $99.60 \pm 11.99 \mathrm{mg} / \mathrm{dL}$ respectively. The difference in the mean values in case and control was not statistically significant with a $p$ value $>0.05$. Similarly, the mean serum creatinine levels in case and control groups were found to be $0.8453 \pm 0.2177 \mathrm{mg} / \mathrm{dL}$ and $0.8157 \pm 0.1346 \mathrm{mg} / \mathrm{dL}$ respectively. The difference between the two groups was not significant $p>0.05$.

The mean TSH concentration in case and control group was $10.30 \pm 3.54 \mu \mathrm{IU} / \mathrm{mL}$ and $3.11 \pm 0.936 \mu \mathrm{IU} / \mathrm{mL}$ respectively and $(\mathrm{p}<0.001)$. The mean FT4 level in case and control was $17.147 \pm 5.73 \mathrm{pmol} / \mathrm{L}$ and $20.32 \pm 5.513 \mathrm{pmol} / \mathrm{L}$ respectively. Though the levels were in normal range, the difference in their mean was very significant, $\mathrm{p}=0.0087$.

The mean homocysteine concentration in case and control groups was $15.129 \pm 2.171 \mu \mathrm{mol} / \mathrm{L}$ and $11.812 \pm$ $1.319 \mu \mathrm{mol} / \mathrm{L}$ respectively and in the unpaired ' $\mathrm{t}$ ' test between the case and control group the two-tailed $\mathrm{p}<0.0001$ which is extremely significant (Figure 1.1). There was extremely significant positive correlation between homocysteine with TSH in the case group ( $\mathrm{r}=0.873$, $\mathrm{p}<0.0001$ ), while a significant negative correlation between homocysteine with FT4 in the case group $(r=-0.40, p<0.05)$.

\begin{tabular}{|c|c|c|c|}
\hline Parameters & Case $(n=45)$ & $\begin{array}{l}\text { Control } \\
(n=45)\end{array}$ & $P$ value \\
\hline Age (in years) & $44.956 \pm 11.668$ & $42.178 \pm 10.562$ & $>0.05^{\mathrm{NS}}$ \\
\hline Sex & $\begin{array}{c}\text { Male } 19 \\
\text { Female } 26\end{array}$ & $\begin{array}{c}\text { Male } 19 \\
\text { Female } 26\end{array}$ & $>0.05^{\mathrm{NS}}$ \\
\hline FPG (mg/dL) & $95.33 \pm 14.151$ & $99.60 \pm 11.99$ & $>0.05^{\mathrm{NS}}$ \\
\hline $\begin{array}{l}\text { Creatinine } \\
\text { (mg/dL) }\end{array}$ & $0.8453 \pm 0.2177$ & $0.8157 \pm 0.1346$ & $>0.05^{\mathrm{NS}}$ \\
\hline $\mathrm{TSH}(\mu \mathrm{IU} / \mathrm{mL})$ & $10.30 \pm 3.54$ & $3.11 \pm 0.936$ & $<0.0001^{\text {*** }}$ \\
\hline FT4 (pmol/L) & $17.147 \pm 5.73$ & $20.328 \pm 5.513$ & $<0.05^{*}$ \\
\hline $\mathrm{HCY}(\mu \mathrm{mol} / \mathrm{L})$ & $15.129 \pm 2.171$ & \multicolumn{2}{|c|}{$11.812 \pm 1.319<0.0001^{* *}$} \\
\hline AST (U/L) & $30.044 \pm 8.298$ & $33.311 \pm 8.268$ & $>0.05^{\mathrm{NS}}$ \\
\hline ALT (U/L) & $41.156 \pm 9.458$ & $40.622 \pm 9.729$ & $>0.05^{\mathrm{NS}}$ \\
\hline \multicolumn{4}{|c|}{$\begin{array}{c}\text { Table 1. Mean } \pm \text { SD of various Parameters } \\
\text { in the Case and Control Groups }\end{array}$} \\
\hline
\end{tabular}

*Significant $(\mathrm{P}<0.05)$, **Very significant $(\mathrm{P}<0.001)$, ***extremely significant $(\mathrm{P}<0.0001)$, NS Not significant $(\mathrm{P}>0.05)$.

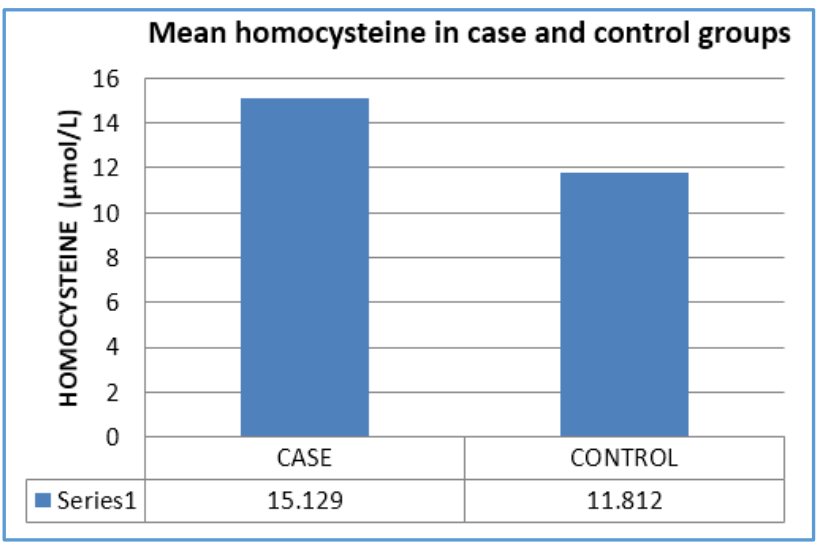

Figure 1. Mean Homocysteine in Case and Control Groups

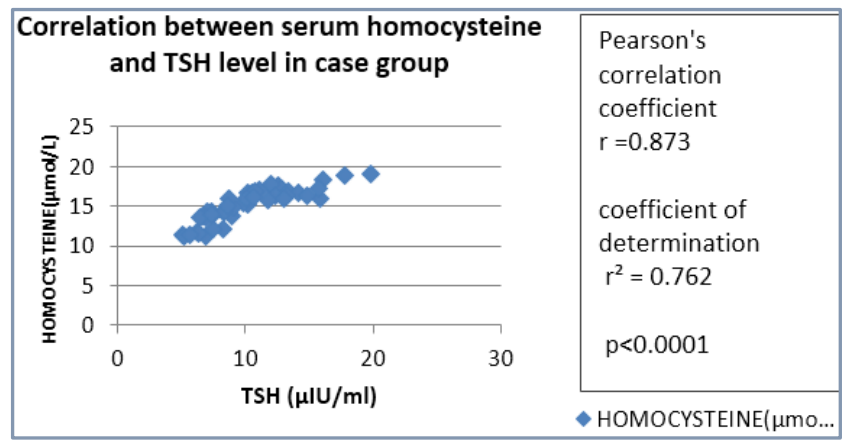

Figure 2. Correlation between Serum Homocysteine and TSH Level in Case Group

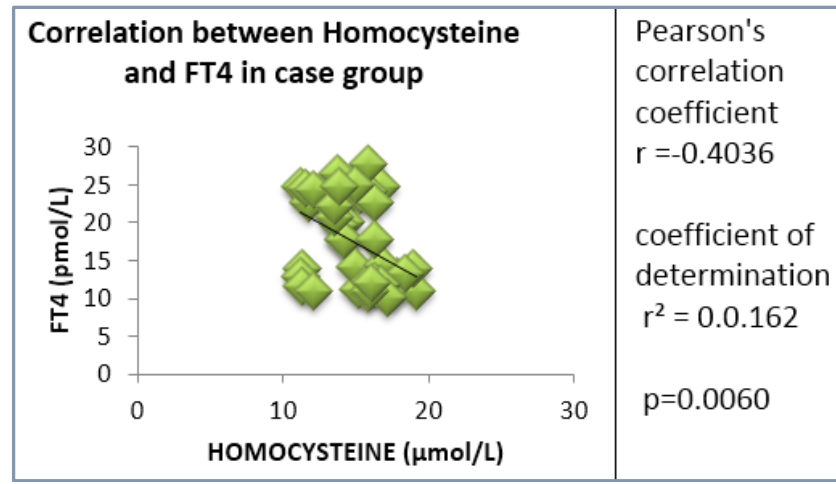

Figure 3. Correlation between Homocysteine and FT4 in Case Group

\section{DISCUSSION}

In recent years, subclinical hypothyroidism is unknowingly emerging as a major public health problem in India and it produces an enormous burden on the economy of the country as it can lead to adverse cardiovascular consequences. Our study was carried out in the Department of Biochemistry, the Department of Medicine and the Department of Endocrinology of Gauhati Medical College and Hospital, Guwahati to analyse the role of homocysteine as a predictive marker for cardiovascular diseases in subclinical hypothyroid cases.

In the present study, the age distribution of the individuals in the study group was between 20 and 75 years. The maximum number of patients were in the age group of 40 - 49 years, in which Serum Homocysteine, TSH and FT4 levels were evaluated. Serum creatinine was estimated to rule out renal pathology. Fasting plasma glucose was done to ensure that the study group was non-diabetic. Serum AST and ALT were done to ensure proper liver function. No difference was observed in the mean fasting plasma glucose, serum creatinine, serum AST and serum ALT levels between case group and control groups ( $p>0.05$ ).

In the present study, the TSH level in case group was significantly higher than the control group. The mean TSH concentration in case and control group was $10.30 \pm 3.54$ $\mu \mathrm{IU} / \mathrm{mL}$ and $3.11 \pm 0.936 \mu \mathrm{IU} / \mathrm{mL}$ respectively. The difference between the means of the two groups was extremely significant $(p<0.001)$. In the study done by Gupta et al, 22 they also found that the mean TSH in the subclinical hypothyroid cases $(13.01 \pm 4.41) \mu \mathrm{IU} / \mathrm{mL}$ were significantly higher than the control group $(2.61 \pm 0.79) \mu \mathrm{IU} / \mathrm{mL}$. Our present study is also supported by the study done by Swaroopa D et al in 2016.23 
In their study, the mean TSH value in case group of subclinical hypothyroid was $8.11 \pm 0.5 \mu \mathrm{IU} / \mathrm{mL}$.

In the present study, the mean FT4 level in case and control was $17.147 \pm 5.73 \mathrm{pmol} / \mathrm{L}$ and $20.32 \pm 5.513 \mathrm{pmol} / \mathrm{L}$ respectively. Thus, it was seen that the mean of the case was lower than that of the control group. Though the levels were in normal range, the difference in their mean was very significant, $p=0.0087$. The findings of our study was in corroboration with the study done by Başak Çakal et al, where the mean fT4 level was lower in SCH patients than in controls $(1.0 \pm 0.1$ and $1.4 \pm 0.2 \mathrm{ng} / \mathrm{dL}$ respectively; $\mathrm{p}<0.001) .{ }^{24}$

The mean Homocysteine level in case group was significantly higher than in control group ( $<<0.005)$. Our present study is also consistent with another study done by Hou $\mathrm{Z}$ et al.25 In their study, they found that the mean homocysteine concentration in the case group was $15.79 \pm$ $6.184 \mu \mathrm{mol} / \mathrm{L}$ and the difference in the mean of homocysteine concentration between the case and the control group was significant $(\mathrm{p}<0.05)$. In the present study, Serum Homocysteine levels in the case group positively correlated with TSH $((\mathrm{r}=0.873, \mathrm{p}<0.0001)$ and negatively correlated with FT4 ( $r=-0.4036, p=0.0060)$. Our study was supported by the study done by Ning Yang ${ }^{26}$ et al, where a similar finding was obtained. In their study, serum homocysteine was negatively correlated with FT4 $(r=-0.504$ and $p<0.01)$ and positively correlated with TSH levels in overt hypothyroidism $(\mathrm{r}=0.461, \mathrm{p}<0.01)$ and in subclinical cases $(\mathrm{r}=0.264, \mathrm{p}<0.05)$. In a study done by Yu WZ, in china during 2015 also found that the difference between the serum homocysteine levels in subclinical hypothyroidism group and the control group was statistically significant $(\mathrm{P}<0.05) .{ }^{27}$

$\mathrm{M}$ Andrees et al21 in their study on "Homocysteine in subclinical hypothyroidism, a risk factor for atherosclerosis" found that the mean fasting homocysteine levels were higher in subclinical hypothyroidism than in the controls $(\mathrm{p}<0.0008)$. Reduced renal excretion and defective metabolism of homocysteine in liver might be the reason behind the elevated levels of plasma total homocysteine in cases of subclinical hypothyroidism.

Again, there was a study on serum homocysteine level in subclinical hypothyroidism done by Sengül E et al 28 in 2004. In this study, the effect of L-thyroxine treatment in patients with subclinical hypothyroidism was evaluated. In the patient group, homocysteine levels prior to treatment were significantly higher than in the control group $(\mathrm{P}<0.001)$. After L-thyroxine treatment, homocysteine levels were reduced significantly. They concluded that homocysteine levels in subclinical hypothyroid patients were in normal range, but when compared with normal healthy control groups the difference was significant.

Amina Godinjak et al did a study to find the link between increased cardiovascular risk and subclinical hypothyroidism in postmenopausal women found that there was increased level of inflammatory markers that leads to a subclinical inflammation in cases of SCH. In their study on postmenopausal women with subclinical hypothyroidism found that there is elevated CRP, homocysteine and TNF- $\alpha$ that increases the risk of cardiovascular diseases in postmenopausal women ( $\mathrm{p}<0.001$ ). In present decade, homocysteine has evolved as a marker of inflammation which is found to be associated with cardiovascular risk in SCH. ${ }^{29}$

\section{CONCLUSION}

Thyroid hormones are catabolic in nature and are involved in various metabolic processes. Though in subclinical state, the levels of FT4 remains in normal range, due to a compensated rise in TSH level, the hormone levels may not be truly normal for every individual. Insufficient thyroid hormone causes defective conversion of riboflavin to its FAD co-enzyme. Thus, there is decreased activity of Methylene tetrahydrofolate reductase enzyme which is a flavoprotein enzyme important in Homocysteine metabolism and thus leads to hyperhomocysteinaemia. Moreover, the kidneys also play an important role in the Homocysteine clearance and metabolism. There may be increased vascular resistance and reduced renal blood flow and reduced GFR. Thus, it reduces its clearance and cause hyperhomocysteinaemia. The results of this study suggest that hyperhomocysteinaemia prevails in subclinical hypothyroid patients. Further, large scale studies are required for better understanding on the role of Homocysteine in the subclinical hypothyroidism and to assess the extent of complications in the disease. Routine screening of TSH in order to diagnose subclinical hypothyroidism and treating them with adequacy will significantly reduce the morbidity and mortality in these patients. As the treatment for hyperhomocysteinaemia is easy and affordable, routine screening of Homocysteine is advisable in subclinical hypothyroids which will significantly reduce the cardiovascular morbidity and mortality in these patients.

\section{ACKNOWLEDGEMENTS}

We convey our gratefulness to the Principal-cum-Chief Superintendent of our institution Prof. (Dr.) A. K. Adhikari (M.D) for allowing us to carry out this research work. Secondly, our most sincere gratitude is for Prof. (Dr.) K. Bhattacharyya MD, MSc in Applied Nutrition (NIN), Head of the Department of Biochemistry for his valuable suggestions throughout the period of study. We also want to thank DBT, New Delhi for providing their financial support towards our study and believing that our study can make a little contribution towards the community.

\section{REFERENCES}

[1] Cooper DS. Clinical practice. Subclinical hypothyroidism. N Engl J Med 2001;345(4):260-5.

[2] Huber G, Staub JJ, Meier C, et al. Prospective study of the spontaneous course of subclinical hypothyroidism: prognostic value of thyrotropin, thyroid reserve and thyroid antibodies. J Clin Endocrinol Metab 2002;87(7):3221-6.

[3] Surks MI, Ortiz E, Daniels GH, et al. Subclinical thyroid disease: scientific review and guidelines for diagnosis and management. JAMA 2004;291(2):228-38.

[4] Col NF, Surks MI, Daniels GH. Subclinical thyroid disease: clinical applications. JAMA 2004;291(2):23943.

[5] Franklyn JA. The thyroid - too much and too little across the ages. The consequences of subclinical thyroid dysfunction. Clin Endocrinol (Oxf) 2013;78(1):1-8. 
[6] The diagnosis and management of primary hypothyroidism. Royal College of Physicians 2011.

[7] Khandelwal D, Tandon N. Overt and subclinical hypothyroidism: who to treat and how. Drugs 2012;72(1):17-33.

[8] Hennessey JV, Espaillat R. Diagnosis and management of subclinical hypothyroidism in elderly adults: a review of the literature. J Am Geriatr Soc 2015;63(8):1663-73.

[9] Fatourechi V. Subclinical hypothyroidism: an update for primary care physicians. Mayo Clin Proc 2009;84(1):65-71.

[10] Hak AE, Pols HA, Visser TJ, et al. Subclinical hypothyroidism is an independent risk factor for atherosclerosis and myocardial infarction in elderly women: the Rotterdam study. Ann Intern Med 2000;132(4):270-8.

[11] Rhbani-Nobar M, Bahrani A, Norazarian M, et al. Int Journal of Endocrinol Metlab 2004;2:103-9.

[12] Tayal D, Goswami B, Koner BC, et al. Role of homocysteine and lipoprotein (A) in atherosclerosis an update. Biomed Research 2011;22(4):391-405.

[13] Guthikonda S, Haynes WG. Homocysteine: role and implications in atherosclerosis. Curr Atherosclerosis Rep 2006;8(2):100-6.

[14] Sydow K, Schwedhelm E, Arakawa N, et al. ADMA and oxidative stress are responsible for endothelial dysfunction in hyperhomocysteinemia: effects of Larginine and $B$ vitamins. Cardiovasc Res 2003;57(1):244-52.

[15] Zhou Y, Cheng Y, Cao X, et al. Association between homocysteine status and hypothyroidism: a metaanalysis. Int J Clin Exp Med 2014;7(11):4544-53.

[16] Welch GN, Loscalzo J. Homocysteine and atherothrombosis. N Engl J Med 1998;338(15):104250 .

[17] Al-Habori MA, Al-Meeri AM, Al-Nuzaily MA, et al. Homocysteine level in relation to thyroid function tests in hypothyroid patients. Asian Journal of Medical and Pharmaceutical Researches 2014;4(2):101-6.

[18] Mamiya S, Hagiwara M, Inoue S, et al. Thyroid hormones inhibit platelet function and myosin light chain kinase. J Biol Chem 1989;264(15):8575-9.
[19] Masaki H, Nishikawa M, Urakami M, et al. 3, 3', 5' Triiodothyronine inhibits collagen-induced human platelet aggregation. J Clin Endocrinol Metab 1992;75(3):721-5.

[20] Ueland PM, Refsum H, Beresford SA, et al. The controversy over homocysteine and cardiovascular risk. Am J Clin Nutr 2000;72(2):324-32.

[21] Andrees M, Boran G, Clarke G, et al. Homocysteine in subclinical hypothyroidism, a risk factor for atherosclerosis? Endocrine Abstracts 2003;5:P280.

[22] Gaurav G, Preeti S, Pradeep K, et al. A correlation between thyroid stimulating hormone and body mass index in women with subclinical hypothyroidism. Asian J Pharm Clin Res 2015;8(4):206-8.

[23] Swaroopa D, Krishna PA, Shetty M, et al. Clinical spectrum of subclinical hypothyroidism and its management - a prospective observational study. Scholars Journal of Applied Medical Sciences 2016;4(9A):3242-7.

[24] Çakal B, Çakal E, Demirbaş B, et al. Homocysteine and fibrinogen changes with l-thyroxine in subclinical hypothyroid patients. J Korean Med Sci 2007;22(3):431-5.

[25] Hou Z, Mu Z, Zhang J, et al. Correlation of blood lipid profile, blood lipid ratio and homocysteine in patients with hypothyroidism. Clinical Medicine Research 2017;6(3):106-10.

[26] Yang N, Yao Z, Miao L, et al. Homocysteine diminishes apolipoprotein A-I function and expression in patients with hypothyroidism: a cross-sectional study. Lipids Health Dis 2016;15:123.

[27] Yu WZ, Yuan D, Fan YX, et al. Correlation analysis of serum lipids, homocysteine and serum uric acid in patients with subclinical hypothyroidism. Chinese J Lab Diagnosis 2015;19:1496-7.

[28] Sengül E, Cetinarslan B, Tarkun I, et al. Homocysteine Concentrations in Subclinical Hypothyroidism Endocr Res 2004;30(3):351-9.

[29] Amina G, Zelija VA, Azra B, et al. Subclinical inflammation: the link between increased cardiovascular risk and subclinical hypothyroidism in postmenopausal women. CMBEBIH 2017;235-40. 